\title{
Measurement of the enzymes lactate dehydrogenase and creatine kinase using reflectance spectroscopy and reagent strips
}

\author{
JF STEVENS* ${ }^{*}$, W. TSANG*, RG NEWALL $†$ \\ From the ${ }^{*}$ Middlesex Hospital Medical School, London, and $\nmid$ Miles Laboratories Limited, Stoke Poges
}

SUMMARY Two new methods for the assay of total activities of lactate dehydrogenase and creatine kinase are described, in which the enzyme activities are measured from a solid-state reagent strip during a kinetic reaction, the reaction being monitored in the ultra-violet region of the spectrum by reflectance spectroscopy. The performances of these methods are evaluated, and compared to conventional "wet" chemistry methods. The solid-phase reagent methods demonstrated precision and accuracy acceptable for diagnostic purposes, and were easy to use by trained operators.

The technique of reflectance spectroscopy, in conjunction with dry, immobilised reagents is becoming more widely used for routine and "stat" analysis within the clinical chemistry laboratory. The chemistries currently available measure the concentrations of substrates, at wavelengths within the visible region of the spectrum. These have been evaluated and discussed elsewhere. ${ }^{1-3}$ In a unique development, enzyme activity can now be measured from a solidstate reagent strip, during a kinetic reaction, the change in absorbance being monitored by reflectance spectroscopy at a wavelength of $340 \mathrm{~nm}$. The first two such enzyme assays are those for the measurement of the cardiac enzymes lactate dehydrogenase (LD-EC 1.1.1.27) and creatine kinase (CK-EC 2.7.3.2.). The two enzymes, lactate dehydrogenase and creatine kinase, have traditionally been used for the diagnosis of myocardial infarction, and for monitoring the progress of the disease, while lactate dehydrogenase is also of value in liver disease.

We report here on the performance of the Ames Seralyzer systems for the measurement of the total activities of the enzymes, lactate dehydrogenase and creatine kinase, as evaluated in a hospital clinical chemistry laboratory.

¥Present address: Department of Chemical Pathology, St Stephen’s Hospital, Chelsea, London, SW10.

Accepted for publication 14 July 1983

\section{Material and methods}

\section{SERALYZER METHODOLOGIES}

The Seralyzer instrument and general principles have been described extensively elsewhere. ${ }^{145}$

\section{Lactate dehydrogenase}

The Seralyzer lactate dehydrogenase method is based on the conversion of pyruvate to lactate, at a temperature of $37^{\circ} \mathrm{C}$ and a total reaction time of $120 \mathrm{~s}$. A measured amount of serum-diluted threefold-is added to the strip, which contains pyruvate and NADH. Lactate dehydrogenase activity is measured by means of reflectance spectroscopy, by the rate of disappearance of NADH at 340 $\mathrm{nm}$ with reference to a calibration curve generated using lactate dehydrogenase calibrators. The test is stated to be linear from 50-450 IU/1; samples with activities above $450 \mathrm{IU} / 1$ can be further diluted threefold with distilled water and reassayed using the DIL key on the instrument, thus extending the assay range. The general outline of the Seralyzer lactate dehydrogenase system is summarised in Table 1.

\section{Creatine kinase}

The Seralyzer creatine kinase method is based on the dephosphorylation of creatine phosphate, the liberated ATP being linked to the glucose/ hexokinase/glucose-6-phosphate dehydrogenase reactions, as outlined in Table 1 . This method is derived from that of Rosalki, ${ }^{6}$ which is a mod- 
Table 1 Principles of Seralyzer lactate dehydrogenase and creatine kinase assay systems

Reaction: lactate dehydrogenase

Pyruvate + NADH lactate dehydrogenase lactate + $\mathrm{NAD}^{+}$

Reaction: creatine kinase

Creatine phosphate + ADP $\frac{\text { creatine kinase }}{\mathrm{Mg}^{++}}$creatine + ATP

$\mathrm{ATP}+$ glucose $\underset{\mathrm{Mg}^{++}}{\stackrel{\text { hexokinase }}{\longrightarrow}} \mathrm{ADP}+$ glucose-6-phosphate

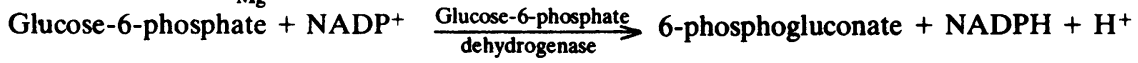

\begin{tabular}{|c|c|c|}
\hline & Lactate dehydrogenase & Creatine kinase \\
\hline $\begin{array}{l}\text { Type of reaction } \\
\text { Principle }\end{array}$ & $\begin{array}{l}\text { Kinetic reaction } \\
\text { Lactate dehydrogenase determined by rate } \\
\text { of increase in reflectance resulting from } \\
\text { disappearance of NADH as reaction } \\
\text { proceeds }\end{array}$ & $\begin{array}{l}\text { Kinetic reaction } \\
\text { Creatine kinase determined by rate of } \\
\text { increase in reflectance resulting from } \\
\text { formation of NADPH as reaction } \\
\text { proceeds }\end{array}$ \\
\hline Dilution required & 1 in 3 & 1 in 9 \\
\hline Further dilution if over-range & 1 in 3 & 1 in 9 \\
\hline Sample size & $30 \mu l$ & $30 \mu l$ \\
\hline Test time & $120 \mathrm{~s}$ & $4 \mathrm{~min}$ \\
\hline Instrument range (normal dilution) & $50-450 \mathrm{IU} / 1$ & To 1000 IU/l \\
\hline Wavelength & $340 \mathrm{~nm}$ & $340 \mathrm{~nm}$ \\
\hline
\end{tabular}

ification of the original Oliver ${ }^{7}$ procedure, subsequently optimised by Szasz et al. ${ }^{8} \mathrm{~N}$-acetyl cysteine is used to reactivate the enzyme, which is rapidly inactivated due to the oxidation of the sulphydryl groups in the active site of the enzyme. Both AMP and diadenosine pentaphosphate are incorporated in the test system to minimise myokinase activity. The reaction is carried out using a 9-fold sample dilution, at a temperature of $37^{\circ} \mathrm{C}$ and a reaction time of $4 \mathrm{~min}$. Creatine kinase activity is determined by measuring the rate of formation of NADPH at $340 \mathrm{~nm}$, with reference to a calibration curve generated using Seralyzer creatine kinase calibrators. The general outline of the Seralyzer creatine kinase test system is summarised in Table 1 .

\section{COMPARATIVE METHODOLOGIES}

The LKB reaction rate analyser was used for both lactate dehydrogenase and creatine kinase methods, employing identical "wet" chemistries to those incorporated in the "dry" form on the Seralyzer systems, (optimised reagents according to the German recommendations, Boehringer Corporation, Lewes), performed at the same temperature of $37^{\circ} \mathrm{C}$.

\section{PROTOCOL}

The objectives were to assess accuracy, relative to a comparative method, using clinical specimens; precision, using commercial controls and clinical specimens; interference; and reliability and acceptability.

\section{Lactate dehydrogenase}

After an initial familiarisation period, accuracy was assessed by the duplicate assay of 138 fresh serum specimens and 25 fresh heparinised plasma specimens routinely submitted to the laboratory, by both $\mathbb{\Phi}$ the Seralyzer and LKB reaction rate analyser, at $\ddot{\theta} \vec{\varphi}$ temperature of $37^{\circ} \mathrm{C}$. Precision was examined by the triplicate assay-by each method-with each run of clinical specimens, of two commercial contro (Hyland Omega I and II) containing normal and raised total lactate dehydrogenase activities, respectively. Total bilirubin and total protein concentrations of the clinical specimens were recorded, so that some indication of the interference by these substances could be assessed. Problems or comments arising during the course of the study were documented.

\section{Creatine kinase}

After an initial familiarisation period, accuracy was assessed by the duplicate assay of 155 fresh heparinised plasma specimens, by both the Seralyzer and the comparative LKB/Boehringer methods at $37^{\circ} \mathrm{C}$. For Seralyzer creatine kinase values above $800 \mathrm{IU} / 1$ (subsequently $1000 \mathrm{IU} / \mathrm{l}$ ), a further ninefold dilution was prepared, and reassayed using the Seralyzer. O The relative bias at different creatine kinase levels $\tilde{O}$ was also assessed. Precision was examined by the triplicate assay of three commercial controls- 0 Beckman Decision Controls A, B and $\mathrm{C}-$ containing different creatine kinase activities.

As a separate study, the effect of EDTA on the $\stackrel{\oplus}{\longrightarrow}$ measurement of creatine kinase by either method, was examined. Any interference, problems or comments were recorded. 
Table 2 Lactate dehydrogenase precision using commercial controls

\begin{tabular}{|c|c|c|c|c|}
\hline & \multicolumn{2}{|l|}{ Seralyzer } & \multicolumn{2}{|c|}{ Comparative } \\
\hline & Omega I & Omega II & Omega I & Omega II \\
\hline $\begin{array}{l}\text { No of runs } \\
\text { No of assays } \\
\text { Mean (IU/f) } \\
\text { Mean Seralyzer bias (IU/l) }\end{array}$ & $\begin{array}{c}12 \\
34 \\
160.5 \\
13.7\end{array}$ & $\begin{array}{c}12 \\
34 \\
354 \cdot 2 \\
-27 \cdot 6\end{array}$ & $\begin{array}{c}12 \\
34 \\
146.8\end{array}$ & $\begin{array}{c}12 \\
34 \\
381 \cdot 9\end{array}$ \\
\hline $\begin{array}{l}\text { Within-run } \\
\text { SD (IU/l) } \\
\text { CV }\end{array}$ & $\begin{array}{l}4.9 \\
3.0 \%\end{array}$ & $\begin{array}{l}10.7 \\
3.0 \%\end{array}$ & $\begin{array}{l}6.4 \\
4 \cdot 4 \%\end{array}$ & $\begin{array}{l}21.4 \\
5.6 \%\end{array}$ \\
\hline $\begin{array}{l}\text { Between-run } \\
\text { SD (IU/I) } \\
\text { CV }\end{array}$ & $\begin{array}{l}11.9 \\
7.4 \%\end{array}$ & $\begin{array}{c}17.5 \\
4.9 \%\end{array}$ & $\begin{array}{l}11.6 \\
7.9 \%\end{array}$ & $\begin{array}{l}35.1 \\
9.2 \%\end{array}$ \\
\hline $\begin{array}{l}\text { Overall } \\
\text { SD (IU/I) } \\
\text { CV }\end{array}$ & $\begin{array}{l}12.9 \\
8.0 \%\end{array}$ & $\begin{array}{l}20.5 \\
5.8 \%\end{array}$ & $\begin{array}{l}13 \cdot 3 \\
9.0 \%\end{array}$ & $\begin{array}{l}41 \cdot 1 \\
10.8 \%\end{array}$ \\
\hline
\end{tabular}

Two controls were assayed in triplicate with each run of clinical specimens. (Different specimens used for each machine.)

\section{Results and discussion}

\section{LACTATE DEHYDROGENASE \\ Precision}

Control serum lactate dehydrogenase precision results are shown in Table 2 . Essentially similar precision at normal lactate dehydrogenase activities is demonstrated by both methods. At raised activities, however, the precision of the Seralyzer is superior to that of the comparative method; this is primarily manifested in the between-run (inter-assay) figures. The mean Seralyzer bias (difference between the

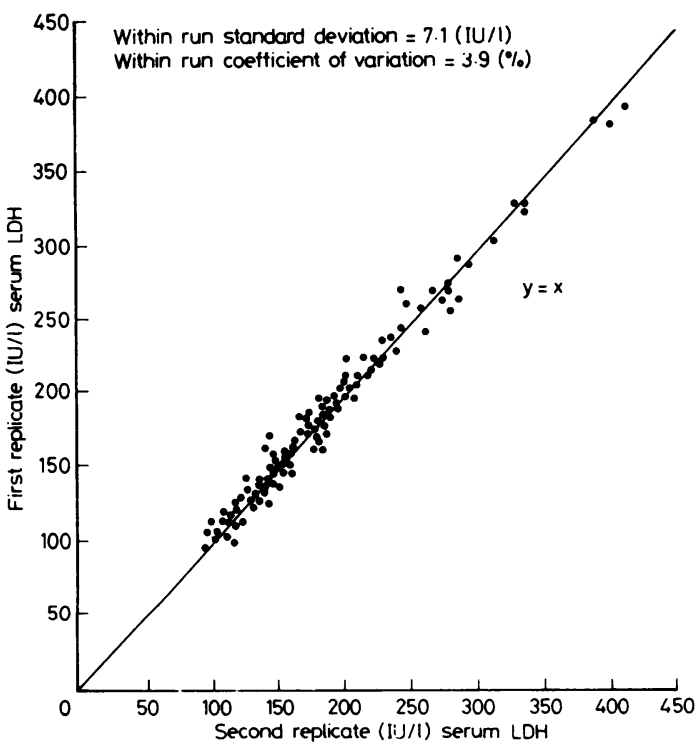

Fig. 1 Seralyzer lactate dehydrogenase precision-comparison of first and second replicates for clinical serum specimens two method means) at each level is relatively small, although in opposite directions. Seralyzer precision was also assessed by use of the duplicate assays performed on the clinical specimens (Fig. 1). The graph, together with the within-run $\mathrm{CV}$ of $3.9 \%$, indicate excellent precision using clinical specimens.

In summary, precision of the Seralyzer system is satisfactory for diagnostic purposes, when using either commercial controls or clinical specimens.

\section{Accuracy}

Linear regression analysis was performed on the lactate dehydrogenase results from 138 clinical serum specimens; the analysis, which is presented in Fig. 2, indicates satisfactory relative accuracy of the Seralyzer system, with a slope approaching unity and a correlation coefficient above 0.9. The concentration-related bias of the Seralyzer relative to the comparative LKB method is presented in Table 3, from which a definite positive Seralyzer bias with respect to the comparative method is apparent. This absolute bias is relatively constant, although the percentage bias shows a marked reduction with increasingly pathological lactate dehydrogenase activities. The use of a comparative method optimised for use at $25^{\circ} \mathrm{C}$ but actually performed at $37^{\circ} \mathrm{C}$-as is common practice in the UK-will have contributed to the observed intercept and relative bias. The bias demonstrated with clinical sera differs from that obtained with the commercial controls (Table 2); perhaps this reflects different behaviour between true and "synthetic" materials. Bearing in mind the variation in performance to be expected from different methods for the assay of enzymes, the Seralyzer lactate dehydrogenase system compared favourably with the LKB reaction rate assay, when used for serum specimens 


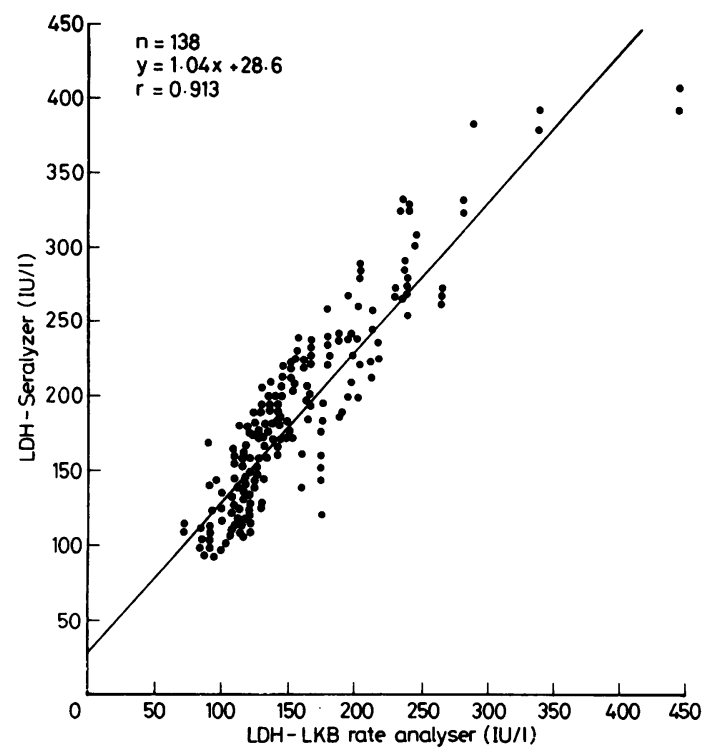

Fig. 2 Lactate dehydrogenase - scatter-plot of Seralyzer and comparative method lactate dehydrogenase values using clinical serum specimens.

at concentrations below approximately $450 \mathrm{IU} / \mathrm{l}$.

Falsely raised lactate dehydrogenase activities are found in haemolysed specimens; the risk of haemolysis is greater during the separation of plasma than of serum. In addition, heparin is a known interferant in certain assays. ${ }^{\prime}$ For these reasons, very brief comparative studies were conducted using serum and heparinised plasma. In the first experiment, 16 clinical plasma specimens were analysed in duplicate by the Seralyzer and the LKB method; there was a highly acceptable correlation coefficient of 0.96 with a marked positive Seralyzer
Table 3 Concentration-related Seralyzer lactate dehydrogenase bias with respect to $L K B$ comparative method, using clinical sera

\begin{tabular}{llll}
\hline $\begin{array}{l}\text { Comparative } \\
\text { lactate } \\
\text { dehydrogenase } \\
\text { level (IUIl) }\end{array}$ & $\begin{array}{l}\text { Seralyzer lactate } \\
\text { dehydrogenase } \\
\text { level (IUIl) }\end{array}$ & $\begin{array}{l}\text { Bias } \\
\text { (IUIl) }\end{array}$ & $\%$ bias \\
\hline 0 & 28.6 & 28.6 & - \\
100 & 132.3 & 32.3 & 32.3 \\
200 & 236.0 & 36.0 & 18.0 \\
300 & 339.8 & 39.8 & 13.3 \\
400 & 443.5 & 43.5 & 10.9 \\
500 & 547.3 & 47.3 & 9.5 \\
\hline
\end{tabular}

bias. In the second experiment, in order to check on the nature and difference of the Seralyzer response to either serum or plasma, and on the relation between lactate dehydrogenase activities in serum and plasma, serum and plasma were separated from whole blood specimens from nine patients. Seralyzer lactate dehydrogenase assays were then performed on these identically-sourced paired sera and plasmas. The findings show a correlation coefficient of 0.9 with no bias - that is, any differences in lactate dehydrogenase activities between serum and plasma specimens, when measured by the Seralyzer, are a true reflection of the actual tissue differences, and are not a function of the differential effect on the Seralyzer system of one or other tissue fluid. This observation could be confirmed by a larger scaleō study.

\section{Interference}

Neither protein-at concentrations of 5 to $9 \mathrm{~g} / \mathrm{dl}(50$ to $90 \mathrm{~g} / \mathrm{l})$-nor total bilirubin-at concentrations up to $3 \mathrm{mg} / \mathrm{dl}(50 \mu \mathrm{mol} / \mathrm{l})$ - produced any interference with the Seralyzer lactate dehydrogenase test. The presence of protein or bilirubin-producing turbid

Table 4 Precision of creatine kinase methods using control sera

\begin{tabular}{|c|c|c|c|c|c|c|}
\hline & \multicolumn{3}{|c|}{ Seralyzer } & \multicolumn{3}{|c|}{ Comparative } \\
\hline & $\bar{A}$ & $B$ & $C$ & $A$ & $B$ & $C$ \\
\hline $\begin{array}{l}\text { Within-run } \\
\text { No of runs } \\
\text { Mean (U/1) } \\
\text { SD (U/1) } \\
\text { CV (\%) }\end{array}$ & $\begin{array}{l}13 \\
56 \cdot 8 \\
3 \cdot 5 \\
6 \cdot 2\end{array}$ & $\begin{array}{r}13 \\
132.6 \\
4.6 \\
3.5\end{array}$ & $\begin{array}{r}13 \\
277 \cdot 4 \\
9 \cdot 2 \\
3 \cdot 3\end{array}$ & $\begin{array}{l}13 \\
47 \cdot 4 \\
3 \cdot 7 \\
7 \cdot 8\end{array}$ & $\begin{array}{r}13 \\
115.0 \\
6.2 \\
5.4\end{array}$ & $\begin{array}{r}13 \\
231 \cdot 3 \\
10 \cdot 1 \\
4 \cdot 4\end{array}$ \\
\hline $\begin{array}{l}\text { Between-run } \\
\text { No of runs } \\
\text { Mean (U/1) } \\
\text { SD (U/l) } \\
\text { CV (\%) }\end{array}$ & $\begin{array}{r}15 \\
56 \cdot 3 \\
4 \cdot 3 \\
7 \cdot 6\end{array}$ & $\begin{array}{r}14 \\
133 \cdot 2 \\
14 \cdot 4 \\
10 \cdot 9\end{array}$ & $\begin{array}{r}15 \\
280.4 \\
27.5 \\
9.8\end{array}$ & $\begin{array}{r}15 \\
47.3 \\
4.0 \\
8.4\end{array}$ & $\begin{array}{r}15 \\
114 \cdot 7 \\
9 \cdot 2 \\
8 \cdot 0\end{array}$ & $\begin{array}{r}15 \\
235 \cdot 8 \\
23 \cdot 8 \\
10 \cdot 1\end{array}$ \\
\hline $\begin{array}{l}\text { Overall } \\
\text { No of assays } \\
\text { Mean (U/l) } \\
\text { SD }(U / 1) \\
\text { CV }(\%)\end{array}$ & $\begin{array}{l}43 \\
56 \cdot 2 \\
5 \cdot 1 \\
9 \cdot 1\end{array}$ & $\begin{array}{r}42 \\
131 \cdot 4 \\
16 \cdot 3 \\
12 \cdot 4\end{array}$ & $\begin{array}{r}40 \\
278 \cdot 6 \\
28 \cdot 0 \\
10 \cdot 1\end{array}$ & $\begin{array}{r}42 \\
47 \cdot 5 \\
4 \cdot 7 \\
9 \cdot 9\end{array}$ & $\begin{array}{r}42 \\
115.5 \\
10.2 \\
8.8\end{array}$ & $\begin{array}{r}41 \\
236 \cdot 7 \\
25 \cdot 2 \\
10 \cdot 6\end{array}$ \\
\hline
\end{tabular}

Three controls were assayed in triplicate with each run of clinical specimens. 
or icteric sera-may interfere with conventional reaction rate lactate dehydrogenase methods, unless appropriate reagent blanks are incorporated. No consistent effects of lipaemia or pigmented sera were apparent on the Seralyzer system.

\section{CREATINE KINASE}

\section{Precision}

Within-run, between-run and overall creatine kinase precision data, obtained by the triplicate assay of Beckman Decision Controls A, B and C with each batch of clinical specimens, are presented in Table 4. Essentially similar precision has been demonstrated by both the Seralyzer and the comparative LKB methods. The positive mean Seralyzer bias at each level will be noted.

\section{Accuracy}

Linear regression analysis was performed on 155 clinical plasma specimens. The regression parameters are presented with the scatter-plot of results in Fig. 3, demonstrating excellent correlation between the Seralyzer and LKB creatine kinase methods.

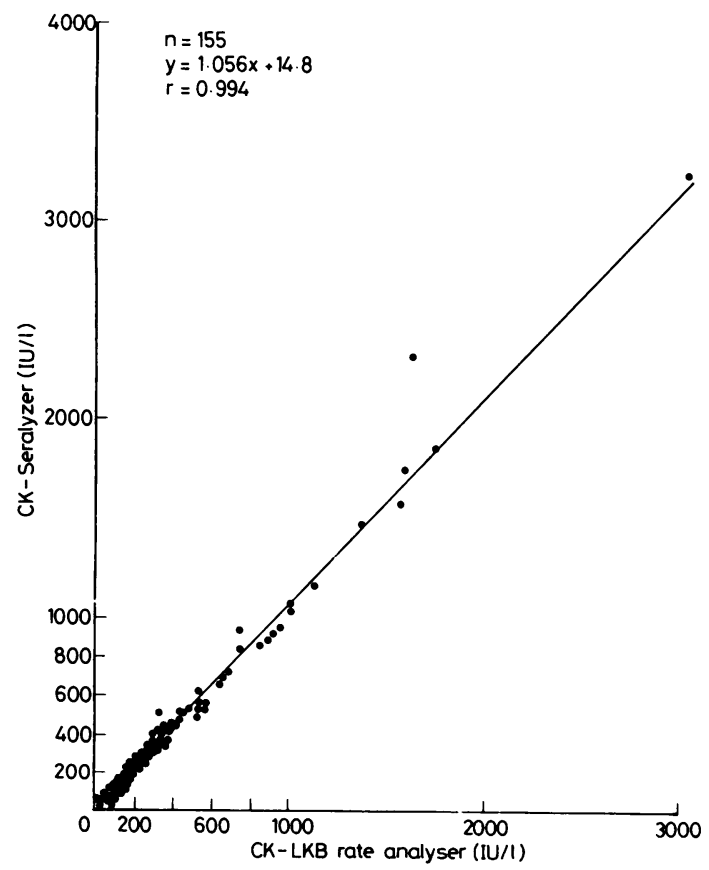

Fig. 3 Creatine kinase - scatter-plot of Seralyzer and comparative method creatine kinase values using clinical plasma specimens. (There were many more points at creatine kinase activities below $400 \mathrm{IU} / \mathrm{l}$; these are not shown here, for the sake of clarity.)
Table 5 Concentration-related Seralyzer creatine kinase bias with respect to $L K B$ comparative method, using clinical plasma specimens

\begin{tabular}{lccc}
\hline $\begin{array}{l}\text { Comparative } \\
\text { creatine kinase } \\
\text { level (U/l) }\end{array}$ & $\begin{array}{l}\text { Seralyzer creatine } \\
\text { kinase level } \\
\text { (U/l) }\end{array}$ & $\begin{array}{l}\text { Bias } \\
\text { (U/l) }\end{array}$ & $\%$ bias \\
\hline 50 & $67 \cdot 5$ & $17 \cdot 5$ & $35 \cdot 0$ \\
100 & $120 \cdot 3$ & $20 \cdot 3$ & $20 \cdot 3$ \\
500 & $542 \cdot 7$ & $42 \cdot 7$ & $8 \cdot 5$ \\
1000 & $1070 \cdot 6$ & 70.6 & $7 \cdot 1$ \\
Mean Bias & & & \\
262.9 & $292 \cdot 3$ & 29.4 & 11.2 \\
\hline
\end{tabular}

The concentration-related Seralyzer creatine kinase bias with respect to the LKB method is presented in Table 5, and again demonstrates a positive Seralyzer bias, which decreases with increasing creatine kinase activity. Such a bias is not unexpected when comparing enzyme methodologies.

As a brief check on the potential difference in Seralyzer performance to be expected when using either serum or plasma, eight paired serum and plasma specimens were assayed in duplicate on the Seralyzer. Very similar results were obtained, with a serum mean creatine kinase activity of $63 \mathrm{IU} / \mathrm{l}$ and a plasma mean of $65 \mathrm{IU} / \mathrm{l}$, over a creatine kinase range from 11 to $114 \mathrm{IU} / \mathrm{l}$.

In view of the fact that the Seralyzer system may be used outside the routine laboratory environment, and since EDTA (sequestrene) is often used to collect plasma samples for haematological purposes, the effect of EDTA on both the Seralyzer and LKB/BCL methods was assessed. Two brief groups of experiments were conducted. In the first, duplicates of 10 sera were assayed on the Seralyzer, subsequently transferred to commercial EDTA tubes (Sterilin) and reassayed on the Seralyzer. The serum specimens were chosen to encompass creatine kinase activity over the range 10-1000 IU/l. The results demonstrate a mean $52 \%$ inhibition of creatine kinase activity, from a mean of $314 \mathrm{IU} / \mathrm{l}$ to a mean of $150 \mathrm{IU} / \mathrm{l}$. In the second study, the creatine kinase activities of paired serum and EDTA plasma specimens were determined by both the Seralyzer and comparative methods. The results are presented in Table 6, and again show a marked-although more variable-inhibition of both methods by EDTA. These studies demonstrate the requirement of the creatine kinase enzyme for activation by bivalent metal cations such as magnesium, which are sequestered by EDTA.

Normal levels of EDTA in Sterilin tubes would not be expected to interfere with either of the creatine kinase methods and therefore a separate study to investigate this is being carried out. 
Table 6 EDTA inhibition of Seralyzer and LKB CK methods*

\begin{tabular}{|c|c|c|c|c|c|}
\hline \multicolumn{3}{|l|}{ Seralyzer } & \multicolumn{3}{|l|}{$L K B$} \\
\hline $\begin{array}{l}\text { Creatine kinase: } \\
\text { serum }(U / l)\end{array}$ & $\begin{array}{l}\text { Creatine kinase: } \\
\text { plasma }+E D T A \\
(U / l)\end{array}$ & \% inhibition & $\begin{array}{l}\text { Creatine kinase: } \\
\text { serum }(U / l)\end{array}$ & $\begin{array}{l}\text { Creatine kinase: } \\
\text { plasma + EDTA } \\
(U / l)\end{array}$ & \% inhibition \\
\hline $\begin{array}{r}256 \\
1072 \\
121 \\
1042 \\
388 \\
9 \\
33 \\
67 \\
34 \\
127\end{array}$ & $\begin{array}{r}191 \\
308 \\
45 \\
556 \\
245 \\
0 \\
19 \\
25 \\
12 \\
101\end{array}$ & $\begin{array}{r}25 \\
71 \\
63 \\
47 \\
37 \\
100 \\
42 \\
63 \\
65 \\
20\end{array}$ & $\begin{array}{r}502 \\
422 \\
51 \\
96 \\
168 \\
208 \\
184 \\
195 \\
1796 \\
357\end{array}$ & $\begin{array}{r}398 \\
119 \\
11 \\
89 \\
142 \\
128 \\
167 \\
33 \\
1037 \\
140\end{array}$ & $\begin{array}{r}21 \\
72 \\
78 \\
7 \\
15 \\
38 \\
9 \\
83 \\
42 \\
61\end{array}$ \\
\hline
\end{tabular}

*Paired specimens collected in plain tubes (serum) and EDTA tubes (plasma).

\section{General}

The Seralyzer systems for the enzymes lactate dehydrogenase and creatine kinase have proved easy to use for experienced personnel, giving, at normal and pathological enzyme activities, accurate and precise results which are acceptable for diagnostic purposes. The precision of the duplicates is such that the operator may rely with confidence on the result of a single assay, thus avoiding excessive replicate testing. Bearing in mind the difference in assay values to be expected between different enzyme methods, and the observed relative Seralyzer bias demonstrated in these studies, approximate "normal ranges" for the Seralyzer lactate dehydrogenase and creatine kinase assays should be established by each laboratory. As an additional component of good laboratory practice, quality control procedures should be followed.

There may be no fundamental difference between the choice of serum or plasma for these Seralyzer assays, although as demonstrated for creatine kinase, the use of EDTA as anticoagulant may lead to decreased values. This would also rule out other anticoagulants which remove magnesium ions. Both Seralyzer methods were reliable during the course of the study; no obvious major faults or errors were observed. The measurement of lactate dehydrogenase and creatine kinase in serum or plasma, using the Seralyzer methodologies, should prove useful in the GP Health Centre, in the private sector, and in the clinical chemistry department for "Stat" analysis, provided that appropriate quality control procedures are observed.

\section{References}

' Stevens JF, Newall RG. Application of reflectance spectroscopy to the estimation of uric acid, urea and glucose: an evaluation of the Ames Seralyzer. J Clin Pathol 1983;36:9-13.

${ }^{2}$ Stevens JF, Tsang W, Newall RG. The measurement of bilirubint cholesterol and creatinine in serum and plasma, using solidō phase reflectance spectroscopy. J Clin Pathol 1983;(in press).

${ }^{3}$ Thomas L, Appel W, Storz G, Plischke W. Determination of blood constituents with dry reagent carriers. Deutsch Med Wochenschr 1981;106:1091-4.

4 Greyson J. Problems and possibilities on dry reagent carriers. J Aut Chem 1981;3:66-70.

${ }^{5}$ Zipp A. Development of dry reagent chemistry for the clinical laboratory. J Aut Chem 1981;3:71-4.

- Rosalki SB. An improved procedure for creatine phosphokinase determination. J Lab Clin Med 1967;69:696-705.

7 Oliver IT. A spectrophotometric method for the determination of creatine phosphokinase and myokinase. Biochem $J$ 1955;61:116-22.

- Szasz G, Gruber W, Bernt E. Creatine kinase in serum: I. Determination of optimum reaction conditions. Clin Chem 1976;22:650-6.

Requests for reprints to: Dr JF Stevens, Department of Chemical Pathology, St. Stephen's Hospital, Chelsea, London SW10, England. 